\section{Synthesis of Hydrastine}

CONDENSATION of nitromeconine and hydrastinine gave a mixture of nitrohydrastines, which was reduced and the product separated into aminohydrastines- $a$ and $-b{ }^{1}$. By the removal of the amino-groups, $d l$. hydrastine- $a$ (m.p. $137^{\circ}$ ) and $d l$-hydrastine- $b$ (m.p. $150-51^{\circ}$ ) were obtained, but at that time neither of these inactive stereoisomerides could be resolved. complicated by recovery and loss of material, and a better method is sought.

There is a great contrast in the ease of resolution of phthalide-isoquinoline alkaloids.

$x$-Bicuculline ${ }^{4}$ has been completely resolved into components, one of which is identical with natural bicuculline (Oxford, collaboration with R. H. IF. Manske), with the greatest of ease by crystallization of the hydrogen $d$ - and $l$-tartrates. On the other hand,
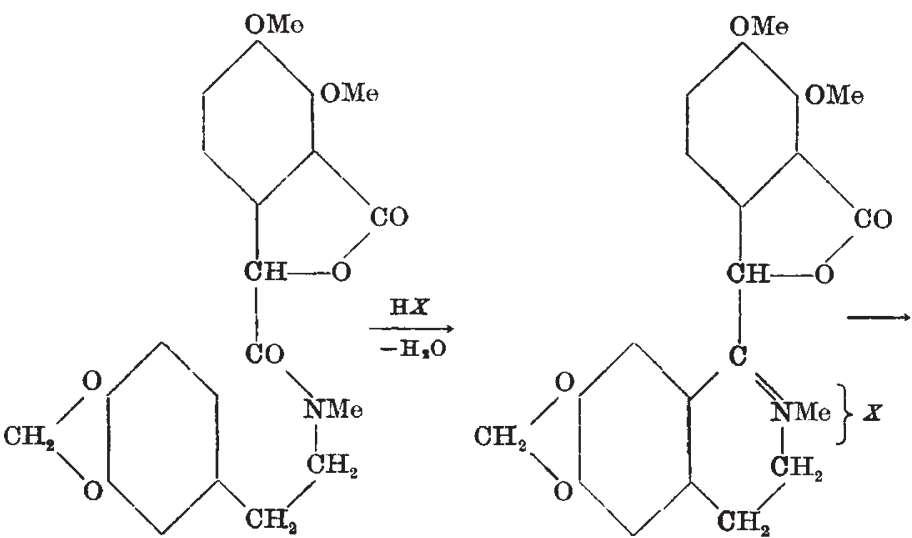

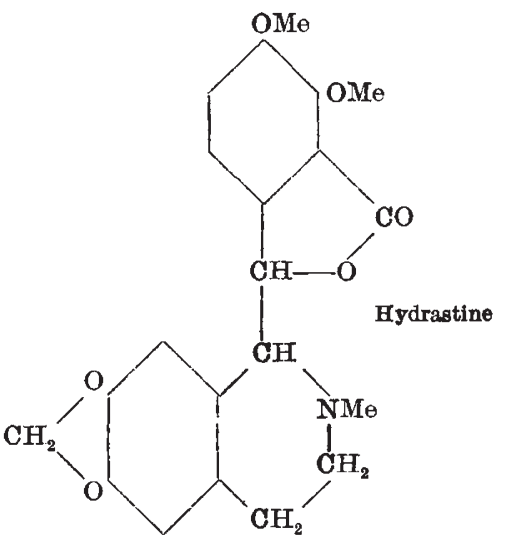

However, by partial racemization of natural l-hydrastine an optically active stereoisomeride was obtained, and a comparison of the rotatory powers made it clear that natural hydrastine and natural narcotine are of different stereochemical configuration ${ }^{2}$. Adopting the convention that natural narcotine is $l$ - $\alpha$-nareotine, partially racemized to $l$ - $\beta$-narcotine, natural hydrastine was considered to be $l-\beta$-hydrastine partially racemized to $l$ - $\alpha$-hydrastine.

The racemization phenomena and the comparison of physical properties of $d l$-amino- $\beta$-narcotine with supposed $d l$-amino- $\beta$-hydrastine suggested that hydrastine- $a$ was $d l$ - $\beta$-hydrastine. As $d l$ - $\alpha$-narcotine (gnoscopine), but not $d l$ - $\beta$-narcotine, could be resolved, it was expected that hydrastine- $b$ should first be split into enantiomorphs and that natural $l$ hydrastine would then be obtained by partial racemization of one of these. This anticipation has not been realized; but instead, hydrastine- $a$ has been directly resolved, and in this way the synthesis of natural hydrastine has been completed.

The present note is a preliminary announcement which will clear the way for publication of independent work in our two laboratories.

At Sheffield a new synthesis of hydrastine and other phthalide-isoquinoline alkaloids has been developed. The substituted $\beta$-phenylethylmethylamide of a substituted phthalidecarboxylic acid is suitably dehydrated with ring-closure and then reduced. Thus for the synthesis of hydrastines the stages are as shown in the scheme above.

Both hydrastine- $a$ (m.p. 138-39 ${ }^{\circ}$ ) and hydrastine- $b$ (m.p. 151-52 ${ }^{\circ}$ ) were obtained in this way, and these melting points were not depressed on admixture with hydrastine- $a$ and hydrastine- $b$, respectively, prepared by the earlier method ${ }^{1}$.

Hydrastine- $a$ was resolved in the course of this work with the aid of $d$-camphor- $\pi$-sulphonic acid, and natural hydrastine was proved to be identical with the product.

The resolution at Oxford by means of $d$-bromocamphorsulphonic acid also afforded a small yield of natural hydrastine, but the process employed was the two $d l$-cordrastines synthesized by the new method (Sheffield) could not be resolved.

A clean separation of hydrastine- $a$ into its components is not easy to effect and the same is true of gnoscopine ( $d l-\alpha$-narcotine), though in this latter case the difficulty is confined to securing a crystal of the salt of the active base.

University, Sheffield.

R. D. Haworth

A. R. Pinder

Dyson Perrins Laboratory,

R. Robinson

University, Oxford.

Dec. 14.

1 Hope and Robinson, Proc. Chem. Soc., 28, 17 (1912). Hope, Pyman, Remfry and Robinson, $J$. Chem. Soc., 236 (1931).

- Marshall, Pyman and Robinson, J. Chem. Soc., 1315 (1934).

Cf. Perkin, Ray and Robinson, $J$. Chem. Soc., 127, 740 (1925).

- Groenewoud and Robinson, J. Chem. Soc., 199 (1936).

\section{Paper Chromatography of some Acridines}

PARTITION chromatography on paper has proved of such general use in biochemistry that, for the time, adsorption chromatography seems to have been neglected. Datta and Overell ${ }^{1}$ have recently shown, however, that vitamin $A$ and its derivatives can be chromatographed on filter paper impregnated with alumina, whereas, owing to the high solubility in lipoid solvents, partition chromatography is un. successful. Even the addition of alumina to the paper is in many cases unnecessary, as was shown by Goppelsroeder ${ }^{2}$ so long ago as 1910. As in ordinary chromatography, the adsorption and elution are governed by the solvent used.

In this communication the separation of pairs of acridine dyes is described. The dyes examined are chemotherapeutic agents, the identification of which in mixtures may be required in the course of clinical research. The acridines examined were atebrin, acriflavine and monacrin (5-amino-acridine hydrochloride), and by development either with water or 